SciDoc

Infer, Interpret \& Inspire Science
International Journal of Dentistry and Oral Science (IJDOS)

ISSN: 2377-8075

\title{
Implant-Supported Fixed Dentures Versus Implant-assisted Over-Dentures: A Prospective Follow up Study of the ability of Prosthetic Rehabilitation in the Mandible to Achieve Patient satisfaction
}

Research Article

Mukatash $\mathrm{GN}^{1 *}$, Zaid R. Al-Zobe ${ }^{2}$

${ }^{1}$ Department of Prosthodontics, Jordan University of Science and Technology, Amman, Jordan.

2 Maxillofacial Fellowship UK.

\section{Abstract}

Background: Clinical experiences showed that most patients prefer the fixed prosthetic replacement of their missing teeth over the removable modalities, therefore this study was conducted to compare implants survival rate, prosthetic rehabilitation results and patient satisfaction in two groups of patients using lower conventional complete dentures which were replaced by either implant supported fixed dentures or implant assisted over-dentures.

Patients and methods: Fifty patients with edentulous mandible were studied. An approval of the different treatment conditions and types for replacement of their lower missing teeth was obtained from all studied patients and the study protocol was approved by the ethical committee of the royal medical services armed forces in Jordan. An implant-supported fixed dentures (ISFDs) were made to half of them, and implant assisted over-denture (IODs) to the other. The implant fixtures were selected with the same length and diameter and inserted by the same clinician. All the delivery of the prosthesis was done after 6 weeks period of the insertion time. The radio-graphical examination and patients' satisfaction were performed after 6 months, 1 year and 3 years.

Results: The survival rate of all implants used for rehabilitation was (100\%). The mean crestal bone resorption was 1.1 (SD $=0.7)$ after 3 years examination period in patients using ISFDs and $1.5 \mathrm{~mm}(\mathrm{SD}=0.7)$ in patients using IODs. Unsurprisingly, patient's satisfaction with ISFDs was higher than that with IODs.

Conclusion: Both the treatment modalities are efficient prosthetic option for mandibular rehabilitation of edentulous mandible. Although many patients still prefer the fixed option, both modalities improved patient satisfaction and oral health quality of life.

Keywords: Fixed Dentures; Over-Dentures Implants; Prosthetic Rehabilitations; Patient's Satisfaction; Crestal Bone Resorption; Prosthetic Complication.

\section{Background}

Prosthetic rehabilitation of an edentulous mandible can be achieved by using a many type of fixed and removable prostheses which are in their support, technical in addition to economical aspects [1]. All have many characteristics which are intended to meet the need of those patients who lose all teeth in the lower jaw and can improve their mandibular function, esthetic and health and quality of life [2]. The end result from the patient's opinion who is wearing prostheses is only partially related to the design and the technical properties of prosthetic rehabilitation modality. In fact, patient satisfaction is primarily based on denture retention therefore would prefer fixed dentures more than any removable prostheses but the selection of the type of the prostheses will greatly influence by the cost $[3,4,5]$.

Over-dentures is usually indicated in the cases where there is no enough bone and it is also considered a cost-effective alternative to a more comprehensive implant supported fixed dentures involving more implants and components [6]. However, over-dentures may not satisfy those patients who desire fixed prostheses or psychologically cannot accept removable prostheses and they may get better results from implant supported fixed prosthesis [7, 8]. Therefore, the treatment modality of choice would raise the treatment to higher clinical standard for success and consequently improves patient satisfaction.

This clinical research was conducted to study implants survival

*Corresponding Author:

Dr. Gadeer E. Mukatash Nimri BDS, MSc

Department of Prosthodontics,Jordan University of Science and Technology, Amman, Jordan. Tel: 962777179100,962799820232

Email: gadeermukatash@hotmail.com,gadeermukatash@gmail.com

Received: April 12,2016

Accepted: May 032016

Published: May 10, 2016

Citation: Mukatash GN, Zaid R. Al-Zobe (2016) Implant-Supported Fixed Dentures Versus Implant-assisted Over-Dentures: A Prospective Follow up Study of the ability of Prosthetic Rehabilitation in the Mandible to Achieve Patient satisfaction. Int J Dentistry Oral Sci. 03(5), 241-247. doi: http://dx.doi.org/10.19070/2377-8075-1600050 
Table 1. Demographic characteristics of the two treatment groups.

\begin{tabular}{|c|c|c|c|c|c|c|}
\hline \multirow{3}{*}{$\begin{array}{l}\text { Group } \\
\text { ISFDs }\end{array}$} & \multicolumn{2}{|c|}{ Age } & \multirow{2}{*}{\multicolumn{2}{|c|}{$\begin{array}{l}\text { Mand bone height } \\
\text { Mean Range }\end{array}$}} & \multicolumn{2}{|c|}{ Gender } \\
\hline & \multicolumn{2}{|c|}{ Mean range } & & & \multicolumn{2}{|c|}{ Male Female } \\
\hline & 55.4 & $35-65$ & 19.1 & $11-29$ & 15 & 10 \\
\hline IODs & 67.6 & $50-69$ & 13.2 & $11-29$ & 13 & 12 \\
\hline Total & 60.5 & $35-69$ & 16.2 & $11-29$ & 28 & 22 \\
\hline
\end{tabular}

Table 2. inclusion characteristics for the studied population.

\begin{tabular}{|l|}
\hline Inclusion characteristics \\
\hline Age between 18 and 80 years old \\
\hline Eood general condition and physical health (ASA class 1 and 2 status) \\
\hline Edentulous lower mandible opposing fixed dentitions for at least 6 months \\
\hline Minimum mandibular bone height equal to 10 mm in the planned implant site \\
\hline Minimum Inter oclusal space equal to 7 mm \\
\hline Willingness to give consent form \\
\hline Exclusion characteristic \\
\hline Medically or psychologically compromised patients under treatment (ASA class 3 and 4 status) \\
\hline Heavy smokers \\
\hline Sever class II or Class III arch relationship \\
\hline Poor upper dental condition (e.g; advance periodontal condition, sever over-erupted teeth, badly destructed teeth \\
\hline Any condition that would interfere with dental implant therapy \\
\hline
\end{tabular}

Table 2. Crestal bone changes in millimeters $(\mathrm{mm})$ after 6 months, 1 year and 3 years of placement of ISFDs and IODs*.

\begin{tabular}{|c|c|c|c|c|}
\hline Type of prostheses & $\begin{array}{c}\text { After 6-months } \\
(\text { Mean } \pm \text { SD })\end{array}$ & $\begin{array}{c}\text { After 1-year } \\
(\text { Mean } \pm \text { SD })\end{array}$ & $\begin{array}{c}\text { after 3 years } \\
(\text { Mean } \pm \text { SD })\end{array}$ & P- value \\
\hline ISFDs & $0.51 \pm 0.6$ & $0.72 \pm 0.5$ & $1.11 \pm 0.7$ & 0.00 \\
\hline IODs & $0.60 \pm 0.7$ & $0.91 \pm 0.8$ & $1.50 \pm 0.7$ & 0.00 \\
\hline
\end{tabular}

$$
P<0.05
$$

rate, inspect the frequency distribution of marginal bone changes to the nearest millimeter after placement of implant supported or retained lower dentures and compare prosthetic results, and patient satisfaction and preference in two groups of patients where lower conventional dentures were replaced by either implant supported fixed dentures or implant assisted over-dentures.

\section{Patients and Methods}

TFifty healthy patients ( 28 men and 22 women) with a mean age of 60.5 years were enrolled in this study (Table-1). All were selected from a pool of patients with all of their missing lower teeth for at least 6 months and were using conventional lower dentures but with persistent complaints of poor retention and stability or general discomfort. An signed conscent form was prepared for the different treatment modalities for replacement of the mandiblular missing teeth was obtained from them.

All patients were examined by a specialized dentist, and only patients who displayed technically successful treatment results were 
Figure 1. Implant Supported Fixed dentures procedure.
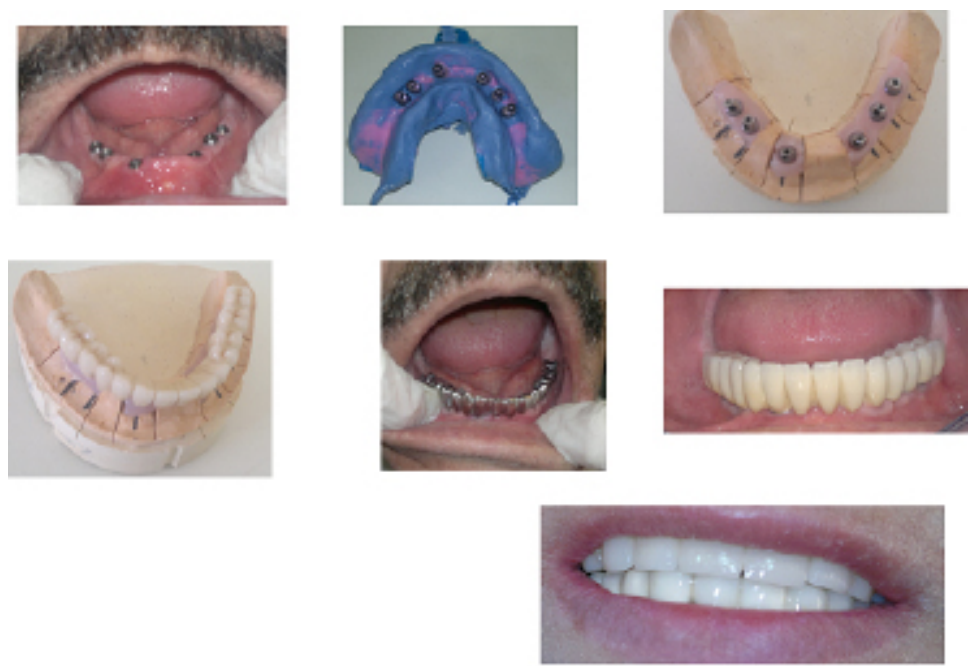

Figure 2. Implant retained over-dentures procedure.
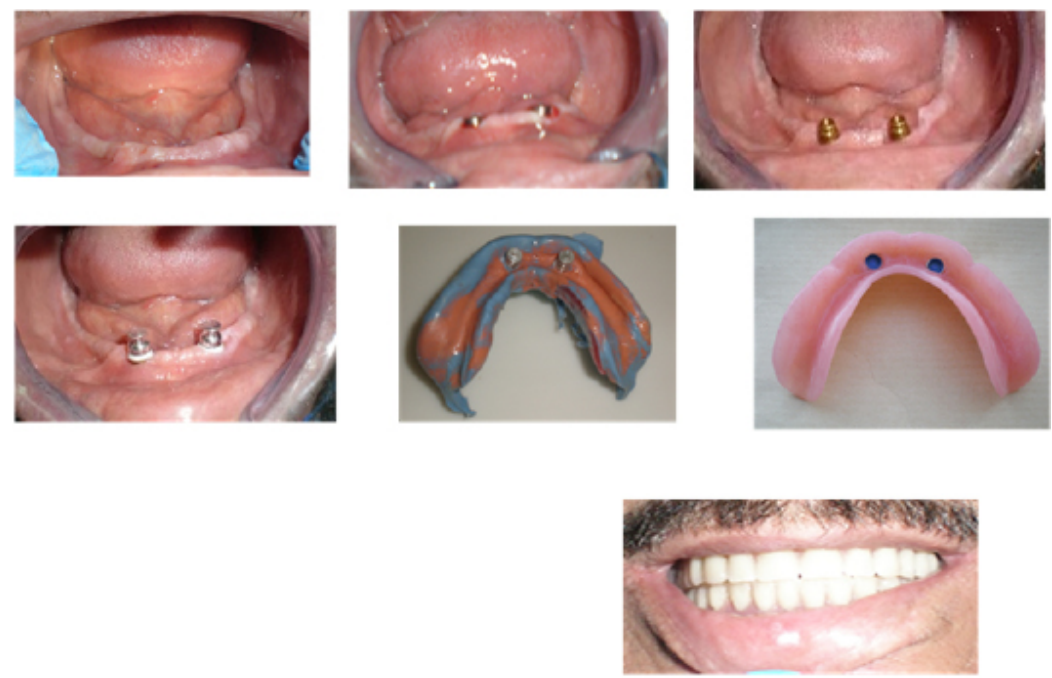

selected (i.e; the inclusion and exclusion criteria were summarized in Table-2). All patients accepted the rules and conditions of this study. The study was approved by the human research ethical committee of the royal medical services armed forces in Jordan (number 9/2015). The treatment protocol was explained by the same author for all the studied patients and a signed consent form was obtained from all of them where they agree all the steps of the treatment, the type of the prostheses of choice and the consequence of prosthetic replacement therapy. A standard recognized method for implant placements was used where half of the studied patients received six implants evenly distributed bilaterally in the mandible while the other half received two implants placed bilaterally in the intraforamental part of the lower jaw. The implant fixtures (Straumann, Wadernburg, Switzerland) were inserted by the same clinician. The implants remained submerged for a period of at least 6 weeks.

25 mandibular ISFDs were accurately fabricated and cemented on six parallel abutments (Figure-1). On the other hand, other 25 IODs retained by two locator denture housings attachments were accurately fabricated and seated on the mandibular supporting tissue and the locators using a standard method (Figure-2).

After implant surgery, immediate implant failure was inspected by removing the mobile implant which gave signs of failure. The radio-graphical examinations and patients' satisfaction were performed by one investigator after 6 months, 1 year and 3 years after insertion of the lower dentures whether it is fixed or removable and then the results data were then recorded.

The intra-oral radiographs were made, using standardized intra oral radiograph with beam direction device and digital sliding gauge as mentioned by Meijer et al (1992, 1993) [9, 10]. Two references were made along the long axis of each implant from a specified to the level of bone. Measurement was done on two opposite sides of each implant. According to the previous researches, it was assumed that the highest crestal bone resorption would have the highest effect on the survival rate of the implants and the prostheses. The lowest score for each implant was recorded as an end result.

To study the subject's oral health and their related quality of life, all studied subjects filled the Oral Health Impact Profile (OHIP49) two times, first time was when they were using conventional dentures and the second time when they were using dentures supported or assisted with implants [2].

To roll out satisfaction with their denture a questionnaire for denture wearers was designed according to the Guckes questionnaire (see Burns et al (1994)) (Figure 3) [11, 12]. The answers dissatisfied 
Figure 3. Denture satisfaction questionnaires (Gucks questionnaires (see Burns et al, 1994)) .

\section{Denture satisfaction}

Subject name :

Subject Number :

Date :

Score :
Appointment name:

Pre implant treatment:

6.0 months after using implant prostheses

lyear after using implant prostheses

3years after using implant prostheses

Below is several questions which will help us better understand how satisfied you are with your denture. Please take a moment to answer the questions by circling the way you feel about them.

(Completely satisfied - CS - there is no problem with the denture; partially satisfied - PS - there are some minor problems; Dissatisfied - DS - there are major problems).

\begin{tabular}{|c|c|c|c|c|}
\hline 1- & Are you satisfied with your appearance when wearing your dentures? & CS & PS & DS \\
\hline 2- & Are you satisfied with the retention and stability of your dentures? & CS & PS & DS \\
\hline $3-$ & Are you satisfied with how well you speak? & CS & PS & DS \\
\hline 4- & $\begin{array}{c}\text { Are you satisfied with the reactions other people have had toward appear- } \\
\text { ance when wearing your dentures? }\end{array}$ & CS & PS & DS \\
\hline $5-$ & Are you satisfied with how well you can chew with your denture? & CS & PS & DS \\
\hline $7-$ & Are you satisfied with the comfort of your lower denture? & CS & PS & DS \\
\hline $7-$ & Are you satisfied with the ease of usage of your denture? & CS & PS & DS \\
\hline $8-$ & Are you satisfied with the ease of cleaning of your denture? & CS & PS & DS \\
\hline
\end{tabular}

Figure 4. Patient satisfaction with conventional dentures, ISFDs and IODs respectively.
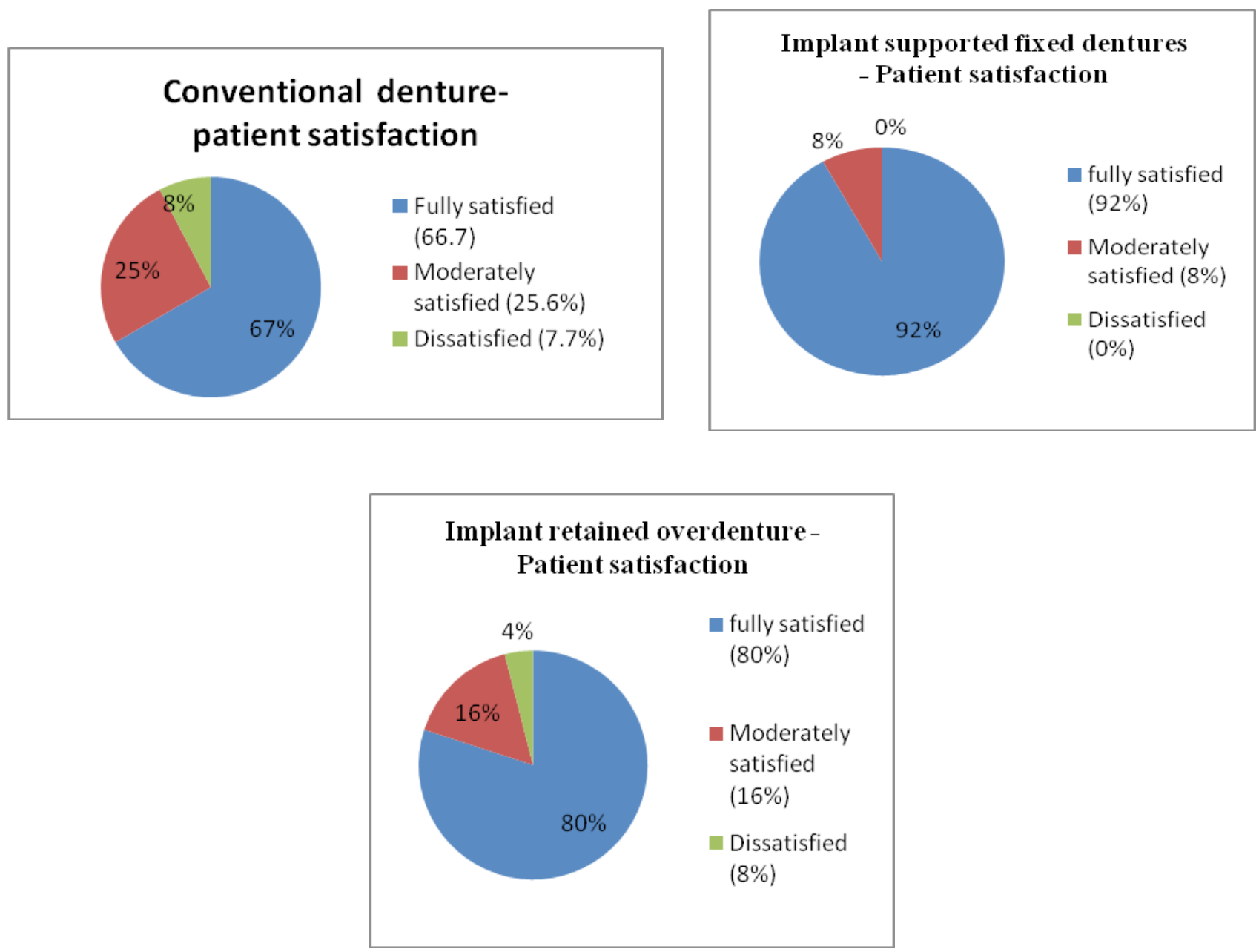
Table 3. Frequency distribution of marginal bone changes to the nearest millimeter per implant 6 months, 1 year and annually after average 3 years of placement of ISFDs and IODs.

\begin{tabular}{|c|c|c|c|c|c|}
\hline & $\geq+1$ & 0 & -1 & -2 & $\leq-3$ \\
\hline After 6-months & & & & & \\
\hline ISFDs & 2 & 135 & 8 & 5 & 0 \\
\hline IODs & 1 & 30 & 13 & 6 & 0 \\
\hline After 1-year & & & & & \\
\hline ISFDs & 0 & 92 & 50 & 6 & 2 \\
\hline IODs & 0 & 19 & 15 & 10 & 3 \\
\hline Average 3 years & & & & & 2 \\
\hline ISFDs & 0 & 89 & 53 & 6 & 4 \\
\hline IODs & 0 & 16 & 17 & 13 & \\
\hline
\end{tabular}

Table 4. Prosthetic success.

\begin{tabular}{|c|c|c|}
\hline Variable & ISFDs $(\mathrm{n}=25)$ & IODs $(\mathrm{n}=25)$ \\
\hline $\begin{array}{c}\text { Number of } \\
\text { patients }\end{array}$ & 25 & 25 \\
\hline Survival & 25 & 25 \\
\hline Repair & 2 & 8 \\
\hline Replace & 0 & 0 \\
\hline
\end{tabular}

Table 5. Incidence of prosthetic complications.

\begin{tabular}{|c|c|c|c|}
\hline Variable & ISFDs (n=25) & IODs (n=25) & Total (\%) \\
\hline Patient discomfort & 3 & 13 & $162 \%)$ \\
\hline $\begin{array}{c}\text { Abutments or locator attachment } \\
\text { loosening }\end{array}$ & 3 & 6 & $6(18 \%)$ \\
\hline $\begin{array}{c}\text { Repair of the teeth or denture } \\
\text { Reline of the denture }\end{array}$ & 2 & 5 & $5(10 \%)$ \\
\hline N/A & & 12 & $12(24 \%)$ \\
\hline Change the rubber mattress & $\mathrm{N} / \mathrm{A}^{*}$ & 47 & 30 \\
\hline
\end{tabular}

$\mathrm{N} / \mathrm{A}=$ not available

satisfied, partially satisfied, completely satutisfied and were coded as 0,1 , and 2 respectively. The satisfaction variable was considered the scores of the eight questions and their answers; the range was from 16 (totally satisfied) to 0 (very dissatisfied) was reflected the results of the patient's answers.

Analysis for the differences was done using the student's $t$-test, SPSS (Statistical Package Social Sciences, version 16, SPSS Incorporated Chicago, IL, USA) at a significant level of 0.05 .

\section{Results}

The prosthesis survival rate was $(100 \%)$. In patients using IS-
FDs, the average crestal bone loss between the base line and the 6 -months period time was $0.51 \mathrm{~mm}(\mathrm{SD}=0.6)$. After 1 year evaluation, it became $0.7 \mathrm{~mm}(\mathrm{SD}=0.5)$ and $1.1 \mathrm{~mm}(\mathrm{~S} . \mathrm{D}=0.7)$ after three years, $0.2 \mathrm{~mm}$ was the mean annual marginal bone loss. In patients using IODs, the average crestal bone resorption between the base line and the 6 -months was $0.6 \mathrm{~mm}(\mathrm{SD}=0.7)$. After 1 year evaluation, it became $0.9 \mathrm{~mm}(\mathrm{SD}=0.8)$ and $1.5 \mathrm{~mm}(\mathrm{SD}=0.7)$ after three years with an average annual bone loss equal to 0.3. The results showed a minimal statistically significant differences between the means crestal bone changes related to the implants supported fixed dentures to those assisted lower dentures where more bone loss was reported in those implants assisted lower over-dentures (IODs) (Table - 2). A frequency distribution of bone loss per implant after 6 - months, 1 year and three years 
Table 6. Mean Oral Health -Related Quality of life (OHIP) scores pretreatment and post-treatment for the two treatment groups.

\begin{tabular}{|c|c|c|c|c|}
\hline & ISFDs & IODs & Post-treatment \\
\hline Domain & Pre-treatment & Post-treatment & 118 & $17.7^{*}$ \\
\hline Total OHIP score & 107.6 & $15.3^{*}$ & 28.5 & 9.7 \\
\hline Functional limitation & 28.4 & 7.6 & 24.3 & 3.5 \\
\hline Physical pain & 16.5 & 3.0 & 24.2 & 7.2 \\
\hline Physical disability & 19.5 & 3.4 & 15.2 & $2.0^{*}$ \\
\hline Psychological difficulty & 14.5 & $0.5^{*}$ & 7.6 & $0.2^{*}$ \\
\hline Social disability & 8.3 & $1.0^{*}$ & 14.5 & $1.0^{*}$ \\
\hline Psychological disability & 11.5 & $1.5^{*}$ & 11.1 & $1.5^{*}$ \\
\hline Handicap & 9 & $1.0^{*}$ & & \\
\hline
\end{tabular}

$P<0.05$

Table 7. Analysis of the patient satisfaction score measurements for ISFD and IODs after 6 months, 1 year and then annually (average 3years) time sequence.

\begin{tabular}{|c|c|c|c|}
\hline Time & CD & ISFD & IRD \\
\hline 6-months & 9 & 22 & 20 \\
\hline 1-year & N/A & 24 & 23 \\
\hline 3 years & N/A & 24 & 24 \\
\hline
\end{tabular}

are listed in (Table -3). Relatively more number of implant with marginal bone resorption was recorded in patients wearing IODs than those using ISFDs.

The cumulative prosthesis survival rate was (100\%) where no implants demonstrated any pain, tenderness or periapical radiolucency during the follow up periods (Table-4).

Table- 5 shows the prosthetic complications. Patients discomfort $(50 \%)$ were the most frequent cause for post adjustment needs for the prosthesis and most of them using the removable prosthesis and need simple adjustment for their prostheses.

The results of the questionnaire which reflect the Oral Health-related quality of life of the studied groups, there were significantly lower (improved) mean post treatment scores than the base line mean scores. Lower (improved) non significant scores for functional difficulties, pain, physical and psychological inability in post treatment ISFDs were reported (Table-6).

Table-7 shows the patient's satisfaction data. The results showed a more statistically significant satisfaction with ISFDs in comparison to IODs $(P$-values $=0.019)$.

\section{Discussion}

The implant's survival rate in this clinical study is $100 \%$ which is comparable to many other reported results on the survival rates of implants supported or assisted dentures and was ranging between $94.5 \%-100 \%[13,14]$.
In agree with the previous studies, $[14,15,16]$ there were radiographically detected marginal bone loss. A statistically significant differences of the average crestal bone loss in the two treatment modalities groups were noted after 6 months, one year and 3 years (more bone loss were found between the patients using IODs than those ISFDs. In the present clinical study, intra-oral radiographs were the method applied and recorded crestal bone resoption which is very similar to the other clinical studies used intra oral radiograph to measure crestal bone resorption $[13,17]$. The average crestal bone resorption was $1.1 \mathrm{~mm}(\mathrm{SD}=0.7)$ in patients using ISFDs, however the results was $1.5 \mathrm{~mm}(\mathrm{SD}=0.7)$ between patients using IODs after 3 years follow up period. A minimal but significant differences between the average crestal bone loss in both treatment methods studied were recorded after one and average three years with more crestal bone loss relared to the implants assisted over dentures (IODs). The relative frequency distribution results of the crestal bone loss per implant during the period of this study indicated that there was relatively more number of implants with marginal bone resorption between patients using IODs than those using ISFDs.

The main prosthetic complications were: sixteenth prostheses adjusted due to roughness, bulkiness, unsatisfactory color or overextension, tenth fractured teeth or denture, fifth reline of the denture, eighth loose abutments or locators and four change of the rubber mattress. In agree with the previous studies, all these prosthetic complications are minor and can be easily adjusted (7).

Heydecke et al. 2003 [18] studied the a group of patients using implant-assisted over-dentures (IODs) in comparison to ISFDs, where a group of them were used over-dentures and the others 
used fixed dentures. The denture retention, stability, aesthetics and ease of cleaning was recorded after delevary. Patients preferred ISFD to IOD, especially where retention was concerned.

The oral health impact profile studies showed that patients can adapted to an implant-assisted over-denture but when some remaining teeth present or when a a patients experiences a history of pain with their old conventional complete dentures they will then prefer the fixed prothodontic replacement choice than any other alternative choice $[19,22]$.

The OHIP-14 comprises 14 items that study seven aspects: functional difficulties, pain, psychological difficulties, physical disability, psychological disability, social disability and handicap. The results were recorded according to Likert scale with five options ranging from the highest "very often" (4) to the lowest "never" (0). [2, 19, 20, 21, 22].

The degree of patient satisfaction is the result of a complex interrelationship between psychosocial and physiological factors [18, $22,23]$. In the present study, patient satisfaction with implantsupported prostheses was assessed based on chewing function, speaking, esthetics, comfort and overall satisfaction using two different scales. The findings showed a greater than $91 \%$ satisfaction rate. Generally, Patient satisfaction is one of the most important indicator of treatment success in prosthetic rehabilitations [15] and success of implant-supported prosthetic rehabilitation should not be judged based solely on clinical parameters but also patient desire.

\section{Conclusion}

Within the limitations of this clinical research, the following conclusion can be withdrawn;

1. Implant supported fixed mandibular denture and implant assisted removable mandibular denture can be considered stable treatment option which can positively affect the patient's satisfaction and their oral health quality of life.

2. After three years follow up period for both treatment modalities no clinically relevant radiographical changes in the marginal bone around different implants in function had been detected.

3. The implant retained removable dentures was needed more post operative care than the implant supported fixed prosthesis, however it was simple.

4. More patients still prefer the fixed option.

\section{References}

[1]. Carlsson GE, Omar R (2010) The future of complete dentures in oral rehabilitation. A critical review. J Oral Rehabil 37(2): 143-156.
[2]. Zani SR, Rivaldo EG, Frasca LCF, Caye LF (2009) Oral health impact profile and prosthetic condition in edentulous patients rehabilitated with implant-supported overdentures and fixed prostheses. J Oral Sci 51(4): 535545.

[3]. Krunić N, Kostić M, Petrović M, Igić M (2015) Oral health-related quality of life of edentulous patients after complete dentures relining. Vojnosanit Pregl 72(4): 307-311.

[4]. Walton JN, MacEntee MI (1994) Problems with prostheses on implants: A retrospective study. J Prosthet Dent 71(3): 283-288.

[5]. Sadowsky SJ (2001) Mandibular implant-retained overdentures: A literature review. J Prosthet Dent 86(5): 468-473.

[6]. Listl S, Fischer L, Giannakopoulos NN (2014) An economic evaluation of maxillary implant overdentures based on six vs four implants. BMC Oral Health 14: 105-113.

[7]. Shetty PK, Shetty BY, Hegde M, Prabhu BM (2016) Rehabilitation of longspan Kennedy class IV partially edentulous patient with a custom attachment-retained prosthesis. J Indian Prosthodont Soc 16(1): 83-86.

[8]. Mehl C, Harder S, Lin J, Vollrath O, Kern M (2015) Perception of dental esthetics: influence of restoration type, symmetry, and color in four different countries. Int J Prosthodont 28(1):60-64.

[9]. Meijer HJA, Steen WHA, Bosman F (1992) Standard radiographs of alveolar crest around implants in mandible. J Prosthet Dent 68(2): 318-321.

[10]. Meijer HJA, Steen WHA, Bosman F (1993) A comparison to asses marginal bone height around endosseus implants. J of Clin Periodontol 20(4): 250253.

[11]. Guckes AD, Smith DE, Sweepe CC (1978) Councelling and related factors influencing satisfaction with dentures. J Prosthet Dent 39(3): 259-267.

[12]. Burns DR, Unger JW, Elswick RK, Giglio (1994) Prospective clinical evaluation of mandibular implant overdenture: part II - patient satisfaction and preference. J Prosthet Dent 73(4): 364-369.

[13]. Naert I, Gizani S and van Steenberghe D (1998) Rigidly splinted implants in the resorbed maxilla to retain a hinging overdenture: a series of clinical reports for up to 4 years. J Prosthet Dent 79(2): 156-164.

[14]. Allen PF, McMillan AS (2003) A longitudinal study of quality of life outcomes in older adults requesting implant prostheses and complete removable dentures. Clin Oral Implants Res. 14(2): 173-179.

[15]. Tavakolizadeh S, Vafaee F, Khoshhal M ,Ebrahimzadeh Z (2015) Comparison of marginal bone loss and patient satisfaction in single and double-implant assisted mandibular overdenture by immediate loading. J Adv Prosthodont 7(3): 191-198.

[16]. Adell R, Lekholm U, Rockler B and Brånemark PI (1981) A 15-year study of osseointegrated implants in the treatment of the edentulous jaw. Int J Oral Surg 10(6): 387-416.

[17]. Meijer HJ, Raghoebar GM, Batenburg RHK, Vissink A (2004) Mandibular overdentures supported by two Brånemark, IMZ or ITI implants: a 5-year prospective study. J Clin Perodontol 31(7): 522-526.

[18]. Heydecke G, Boudrias P, Awad MA, De Albuquerque RF, Lund JP, et al. (2003) within-subject comparisons of maxillary fixed and removable implant prostheses: Patient satisfaction and choice of prosthesis. Clin Oral Implants Res 14(1): 125-130.

[19]. Albaker AM (2013)The oral health-related quality of life in edentulous patients treated with conventional complete dentures. Gerodontology 30(1): 61-66.

[20]. Fernandez-Estevan L1, Selva-Otaolaurruchi EJ, Montero J, Sola-Ruiz F (2015) Oral health-related quality of life of implant-supported overdentures versus conventional complete prostheses: Retrospective study of a cohort of edentulous patients. Med Oral Patol Oral Cir Bucal 20(4): 450-458.

[21]. Turkyilmaz I1, Company AM, McGlumphy EA (2010) Should edentulous patients be constrained to removable complete dentures? The use of dental implants to improve the quality of life for edentulous patients. Gerodontology 27(1): 3-10.

[22]. Van Waas MA (1990) The influence of psychological factors on patient satisfaction with complete dentures. J Prosthet Dent 63(5): 545-548.

[23]. Baracat LF, Teixeira AM, Santos MBF, Cunha VP, Marchini L (2011) Patients' expectations before and evaluation after dental implant therapy. Clin Implant Dent Relat Res 13(2): 141-145. 